\title{
Polypropylene Mesh in Minimally Invasive Treatment of Female Stress Urinary Incontinence
}

\author{
NICOLAE GRIGORE, VALENTIN PIRVUT, IONELA MIHAI*, ADRIAN HASEGAN, ELISABETA ANTONESCU, \\ LILIANA COLDEA, SEBASTIAN IOAN CERNUSCA MITARIU \\ Lucian Blaga University of Sibiu, Faculty of Medicine, 2A Lucian Blaga Str., 550169, Sibiu, Romania
}

\begin{abstract}
Stress urinaryincontinence in women is a condition widelyencountered in the entire world with a prevalence between $12.8 \%$ and $46.0 \%$. Stress urinary incontinence is a public health problem causing a significant decrease in quality of life, involving social, physical, psychological, occupational and sexual suffering of patients. The minimal invasive treatment of the stress urinary incontinence (SUI) consists in fixing a suburethral polypropylene mesh (SPM) in retropubic (TVT) or transobturator (TOT) space, in order to regain the pelvic support of the urethra, with the consecutive augmentation of the pressure of urethral closing during effort. The objective of this paper is to present the advantage of SPM in the SUI treatment in the eleven years' experience of Department of Urology Sibiu.
\end{abstract}

Keywords: polypropylene mesh, stress urinary incontinence, minimally invasive treatment, transobturator, urogenital prolapse

Urinary incontinence is the involuntary loss of urine through the urinary meatus. Urinary incontinence is not a normal consequence of aging [1].

Stress urinary incontinence in women is a condition widely encountered in the entire world with a prevalence between 12.8 and $46.0 \%$. Stress urinary incontinence is a public health problem causing a significant decrease the quality of life, involving social, physical, psychological, occupational and sexual suffering of patients [2].

The treatmentoptions include: conservatory treatment, classic surgical treatment or minimal invasive surgical treatment.

The minimal invasive treatment of the stress urinary incontinence (SUI) consists in fixing a suburethral polypropylene mesh (SPM) in retropubic (TVT) or transobturator (TOT) space, in order to regain the pelvic support of the urethra, with the consecutive augmentation of the pressure of urethral closing during effort.

The word prosthesis comes from the Greek language and is translated through placing before. It was used in the antique literature to designate a separate word, opposed to the word prefix. In surgery prosthesis or meshes defines an artificial material of different forms and dimensions used to replace probably a body defect [3]. It seems that using prosthetic matherials began since the antiquity, when people believed that Heliodorus from Chos used for the first time, in the year 25 , cotton cellulose to accentuate the cicatrization from the inguinal region, after the surgical cure of a hernia [4].

The synthetic matherials appeared in the SUI surgery as an alternative to the autologous fascia, with the aim of decreasing the surgery time, the post-surgery pain, and the duration of hospitalization and theoretically of increasing the durability of the post-surgery results [5].

Theoretically, the ideal material should have durability at least as the patient's life, without risk of degradation or breakage as exists in the case of the autologous fascia.

It should poses one or more, ideally all, of the following characteristics: pliable, strong, non-allergenic and with perfect tissue integration behaviour [6].

Polypropylene (- $\mathrm{CH} 2-\mathrm{CH}(\mathrm{CH} 3)$-) $n$ is a thermoplastic discovered in 1956 by Giulia Nata by isotactic polymerization of ethylene. The polypropylene resistance is similar to iron, although it has 1/8 of its density. It is resistant to biological degradation and it is waterimpermeable. It is not subject to enzymatic degradation in vivo; It high resistance to high temperatures (up to 168 degrees C), so it can be sterilized without its properties being altered. The product wire is continuous, monofilament and non-resorbable. The polypropylene mesh is knitted by crochet[7]. According to Amid's classification, there are four types of mesh : type I macroporous (with pores $>75$ microns), type II total microporous (with pores $>75$ microns), type III macroporous total with microporous multifilament component and type IV - biomaterials with submicron pore size[8].

Only type I, macroporous polypropylene mesh fulfilled the expected desideratum, referring to the biocompatibility and tissue integration.

The concept of SPM in minimal invasive treatment of SUI was introduced in 1995 by Ulmsteen $U$ and Petros $P$ [9]. The model that was used is Gynecare, FallsChurch and VA. This has at its basis the prosthesis of Prolene (Ethicon, Somerville NJ USA) that is also a polypropylene mesh. It has been clinically available since 1970 without having its structure modified. Its thickness is of $0.027 \mathrm{~cm}$. and has a weight of $0.0743 \mathrm{~g} / \mathrm{cm}^{2}$. The pores dimensions and the thickness of the producthave a significantly impact on rigidity. Those factors will influence the degree of the scar infiltration of the host tissue. It has a macroporous structure with pores greater than 75 microns in any of the three dimensions. The large pore size ensures good penetration with macrophages, neutrophils, fibroblasts and collagen fibers in order to inhibit bacterial growth and increase connective tissue fibrosis.

One important thing is the cost of materials. It can be used directly through prefabricated kits with higher costs or tailored directly by the surgeon from a larger size mesh. Finally the perioperative cost is is much lower[10].

TVT technique was described by UImsten in 1995 and is based on the fitting of SPM through the retropubic passage [11] (fig.2, fig.5).

\footnotetext{
* email: office@urologiesibiu.ro; Phone: 0745381064
} 
TOT technique described by Delorme in 2001 involves the fitting of the SPM through the transobturator passage, avoiding bladder injury that may occur in TVT technique regarding the retropubic passage of the operator device[ 12] (fig.3, fig.4).

The objective of this paper is to present the advantage of SPM in the SUI treatment in the eleven years' experience of Urology Department Sibiu.

\section{Experimental part}

Between December 2005-2017, 455 patients with stress urinary incontinence (SUI) were evaluated at the Urology Clinic of Sibiu. Diagnostic algorithm consisted in clinical examination, ultrasound, urine analysis, urine culture, bioumoral examination, micturition diary filled out by patients for 7 days pre-surgery. The quality of life was initially evaluated with two questionnaires: Urogenital Distress Inventory (UDI- 6) and Impact Incontinence Quality of Life (IIQ-7). The subjective perception of the treatment's satisfaction was evaluated through the TSS questionnaire (Treatment Satisfaction Scale).

The patients with urinary incontinence by medium and severe urinary urgency within overactive bladder syndrome were excluded.

In order to quantify the degree of severity of SUI, Stamey classification was used: grade $1(220 \mathrm{p} / 48.36 \%)$, grade 2 (218 p/47.91\%), grade $3(17 p / 3.73 \%)$.

We used the commercially available ordinary $30 \times 30 \mathrm{~cm}$ non-absorbable monofilament macroporous polypropylene mesh used in herniorrhaphy (polypropylene mesh; Prolene, Ethicon Ltd., UK) after tailoring it to give a strip $15 \mathrm{~cm}$ long and $2 \mathrm{~cm}$ wide.

The surgical treatment consisted of TVT technique in $102 \mathrm{p}(22.42 \%)$ and of TOT technique in $353 \mathrm{p}(77.58 \%)$. The operations were performed under spinal anaesthesia, patients receiving antibiotic prophylaxis with 3 doses of cefuroxime intravenously. Urethro-vesical catheter was removed $24 \mathrm{~h}$ after intervention.

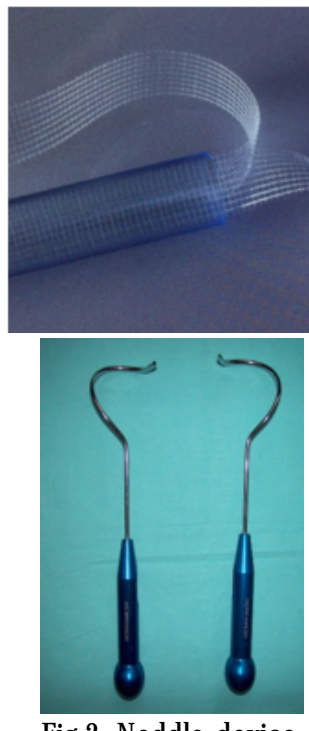

Fig.2. Neddle device used in TOT

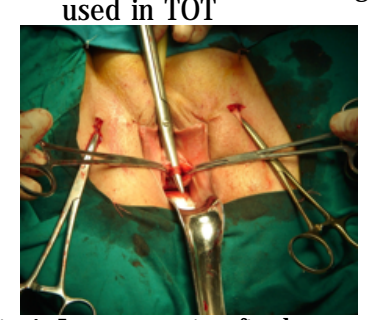

Fig.4. Intraoperative final aspect of SPM using TOT technique

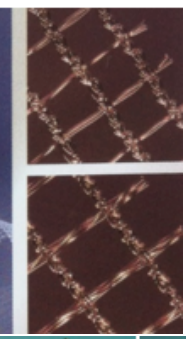

Fig. 1. Macroporous monofilament polypropylene mesh use in SUI treatment

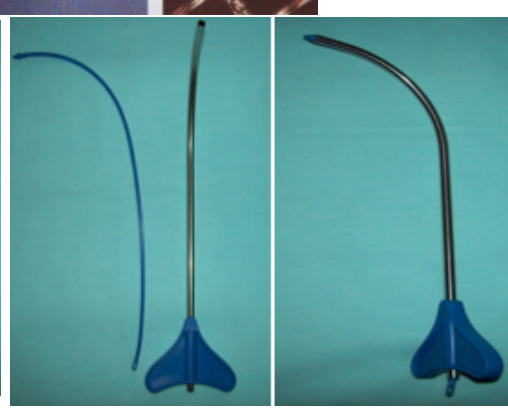

Fig. 3. Neddle device used in TVT technique

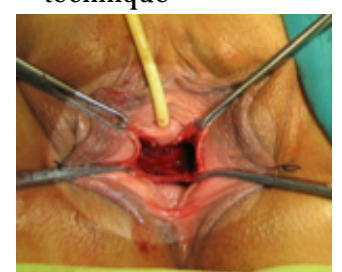

Fig. 5. Intraoperative final aspect of SPM using TVT technique
In our study group, urogenital prolapse correction associated to stress urinary incontinence was performed at $79 p(17.36 \%)$ : vaginal hysterectomy (6p), anterior colpoperineoraphy with Kelly plication in patients with cystocele (3p), cystocele cure with Prolene prosthesis (29 p), posterior colpo-perineorrhaphy in the patients with associated rectocele (24 p), anterior and posterior colporraphy with dual Prolene mesh in patients with associated cystorectocele (17p).

Patients were followed up every 2 weeks during the first month, then every 3 months in the first year postsurgery and then yearly.

The median postoperative follow-up was on average 62 months ( $72 \pm 13$ months).

The protocol of the follow-up visits consisted of anamnesis, the micturition diary completed by the patient 7 days before the visit, the clinical examination with the cough test and the Valsalva maneuver in dorsal decubitus and in clinostatism, abdominal ultrasound, questionnaires for assessing the quality of life: UDI-6, IIQ-7. The degree of amelioration of the initial symptoms through the TSS questionnaires was also studied.

\section{Results and discussions}

The largest share in the studied group is given by the TOT technique with $77.58 \%$ of surgeries (353/455p).

The average operating time was $23.1 \mathrm{~min}$, an average of $30.8 \pm 9.3 \mathrm{~min}$ for the TVT technique and $15.4 \pm 4.7 \mathrm{~min}$ for the TOT technique.

Urogenital prolapse concomitant correction prolonged the surgical time by 55 min on average.

Resumption of micturition 24 hours later was similar in both groups.

The average length of stay was on average 3.2 days, 3.4 \pm 1.8 days) for the TVT technique and $3.1 \pm 1.2$ days for the TOT technique. There was no difference between the two techniques regarding the length of stay.

Intraoperative complications were: vaginal fornix lesion at $1.13 \%(4 p / 353 p)$ and bladder injury at 0.84\% (3p/353p) in the TOT group (7p-1.98\%); bladder injury at $5.88 \%(6 \mathrm{p} /$ $102 p)$ and retropubian hematoma at $2.94 \%(3 p / 102)$, vaginal erosion $1.96 \%$ (2p/102p), bladder injury $0.98 \%$ (1p/ $102 p)$ in the TVT group (12p-11.76\%).

The risk of bladder injury is greater TVT technique. Therefore performing cystoscopy is necessary to check the integrity of the bladder.

Bladder injury suspicion can be raised if, when pulling the TVT or TOT device, there appears sudden bleeding in wound or the urine from the bladder probe becomes hematuric. If bladder injury is confirmed, the prosthesis should be removed, the lesion should be sutured and the prosthesis will be reassembled afterwards, usually after more than three months.

It is not necessary to perform cystoscopy either in TOT technique because the tip of the device can'tbe controlled by the surgeon throughout the lateral vesical retropubic traject.

Postoperative complications were: vaginal erosion at $1.13 \%(4 p / 353 p)$, recurrence of incontinence at $1.98 \%(7 p /$ $353)$, de novo urgency at $0.28 \%$ ( $1 p / 353)$ in the TOT group (12p-3.39\%); vaginal erosion at $1.96 \%$ ( $2 p / 102 p)$, de novo urgency at $5.88 \%(6 \mathrm{p} / 102)$ in the TVT group ( $8 p-7.84 \%)$.

Vaginal erosion was found in our study at $1.96 \%$ (2p) for TVT and $1.13 \%$ (4p) for TOT. The pacients were treated by performing local excision of the mesh underneath the uretra and local oestrogen, follow by secondary healing of the vaginal mucosa. 
The exact pathophysiology of vaginal erosions given by the mesh material is not fully understood. Different factors may predispose a patient to erosion: poor surgical technique, genital atrophy, poorly estrogenized tissue, previous vaginal surgery, concomitant procedures and local infections and high body weight [13].

Liapis et al [13] reported a vaginal erosion rate of $2.1 \%$ in the TVT technique (46p) compared to $0 \%$ for the TOT technique (43p) at a 12-month postoperative follow-up.

Postoperative complication rate is low, regardless of the operative technique performed (TVT or TOT).

Overall continence rate in our study group was of $98 \%$ (446 p/455 p). Postoperative continence rate was of $97.2 \%$ $(7 p / 353 p)$ in the TOT group and of $100 \%(102 p / 102 p)$ in the TVT group.

Patients in the TOT group, in whom incontinence persisted postoperatively (7p/353p) had grade 3 of SUI. They were all operated again using TVT technique. All patients were dry after surgery and at the follow-up examination. All patients in the TVT group were continent after surgery regardless of the preoperative incontinence grade.

The postoperative results after TOT and TVT published by Neuman have shown good efficacy in the cure of stress urinary incontinence and a lower rate of intra-and postoperative complications [15]

A retrospective study is performed by Horton et al. comparing 47 patients who benefited from TVT technique along with vaginal corrective interventions, with 133 patients who underwent only TVT technique [14]. No intraoperative complications occurred in the operated patients; bleeding was minimal; urethro-vesical catheter was kept with more than $24 \mathrm{~h}$ as compared with the patients requiring only SUI correction ( $48 \mathrm{~h}$ ). Postoperative continence was good, the patients being dry at the monitoring check-ups.

In our study the correction of the urogenital prolapse did not negatively influence resumption of micturition and postoperative continence cure.

It is recognized that proper identification and correction of defects of the diaphragm pelvis in the same surgical session of correcting urinary incontinence, significantly improves the surgical outcome [13].

Several studies have reported clinical outcomes of patients who received TVT or TOT simultaneously with the solving of the urogenital prolapse. Only a few studies have correctly evaluated the safety and efficacy of TVT and TOT in combination with pelvic reconstructive surgery. The incidence of urogenital prolapse that needed surgical correction concomitant with the intervention for SUI was reported at a rate of $42 \%$ [ 13$]$.

Immediate postoperative continence $(24 \mathrm{~h}$ after removing the urethro-vesical catheter) and at during the follow-up period was good, as judged by the clinical examination and micturition diary.

There have been assessed the degree of postoperative urinary continence and quality of life of patients undergoing surgery, as well as the technical issues of sub-urethral mesh fixing in both techniques TVT and TOT.

The two questionnaires UDI- 6 and IIQ-7 can quantify the degree of severity of urinary incontinence. The severity rate of urinary incontinence measured by UDI- 6 and IIQ-7 showed a significant improvement of continence after surgery in both groups.

Postoperative satisfaction rate assessed during the follow-up by the TSS questionnaire was performed by of 87\% (396 patients).

In our study the rate of post-surgery satisfaction evaluated through the TSS questionnaire was of $95.2 \%$ (377p). Treatment was considered an success by $356 p$ (95.38\%). Twenty-one patients considered that the treatment was a failure (4.62\%). Those patients had either persistent post-surgery urgency $(14 \mathrm{p} / 3.07 \%)$, or postsurgery de novo urgency ( 7 patients/1.55\%).

Assessing the impact of urinary incontinence on the quality of life of patients is important in the preoperative evaluation of patients [16].

Although it is a subjective evaluation, patient satisfaction is an important parameter in determining the success of surgery, aimed at improving the patients' quality of life. The pre-operative urgency associated to the urinary effort incontinence was the only predictive factor that had a negative influence on the post-surgery satisfaction [17].

\section{Conclusions}

Polypropylene macroporous monofilament mesh remains the best prosthetic material in order to strengthen pelvic support of the urethra.

Sub-urethral polypropylene mesh (SPM) is an safe and effective treatment in SUI irrespective of the chosen technique (TOT or TVT).

Acknowledgements: This study, being a retrospective one, did not require a written consent from the patients involved. The authors declare no conflict of interests and no sponsorship was provided by the manufacturer of the mesh involved in this study. All authors have read and approved this publication and had equal scientific contribution in publishing this material.

\section{References}

1.SANDIP P., RODNEY A., PETTER K., SHLOMO R. Anterior Vaginal Suport, In: Female urology, urogynecology and voiding dysfunction:Dekker 2005:3-20.

2.THOM D. Variation in estimates of urinary incontinence prevalence in the community: effects of differences in definition, population characteristics, and study type. J Am Geriatr Soc 1998; 46(4):473-480. 3.MOSBY'S MEDICAL, Nursing\&Alled Health Dictionary, Mosby, 2000,6. 4.KINGNORTH A, LEBLANCK, Management of Abdominal Wall Hernias 2003;7:78-104.

5.GAVRILAS F, OPREA V, Chirurgia peretelui abdominal, Vol. 1, Ed. Medicalã Universitarã luliu Hatieganu, 2006;163-199.

6.BRATU, D, BOICEAN, A, TANASESCU, C, SOFARIU, C, MIHETIU, A, CERNUSCA MITARIU, IS, OGNEAN, L, MOLDOVAN,C, BOITOR, C, Textile Polypropylene Allografts and their Postoperative Tissue Reaction in the Surgery of Inguinal Hernia, Mat. Plast., 54, no.1, 2017, p.119

7.GILBERT A. I, GRAHAM M.F, YOUNG J. Polypropylene the standard of mesh materials in SCHUMPELICK V, NYHUS L.M (eds): Meshes: Benefits and Risks (2004) pag.101-105, Edit. Springer, Berlin 8.AMID P.K. Classsification of biomaterials and their related complications in abdominal wall hernia surgery. Hernia (1997)1:1521.

9.ULMSTEN U, PETROS P. Intravaginal slingplasty (IVS): an ambulatory surgical procedure for treatment of female urinary incontinence. Scand J Urol Nephrol 1995; 29:75-82.

10.MOHAMMED S. ELSHEEMY, HISHAM GHAMRAWYA HESHAM FATHY, HUSSEIN A. HUSSEIN, EMAN A. HUSSEIN, AHMED ALY, AND SHERIF ABDEL RAHMAN. Use of surgeon-tailored polypropylene mesh as a needle-less single-incision sling for treating female stress urinary incontinence: Preliminary results. Arab J Urol. 2015 Sep; 13(3): 191198

11.ULMSTEN U, PETROSP. Intravaginal slingplasty (IVS) : an ambulatory surgical procedure for treatment of female urinary incontinence. Scand J Urol Nephrol 1995; 29:75-82.

12.De LORME E. La bandelette trans-obturatrice: un procede miniinvasif pour traiter l'incontinence urinair d'effort de la femme Prog. Urol. 2001; 11:1306-1313. 
13.LIAPIS A, BAKAS P, GINER M, et al. Tension-free vaginal tape versus tension-free vaginal tape obturator in women with stress urinary incontinence. Gynecol Obstet Invest 2006;62:160-164.

14.HORTON TR, DRUCKENMILLER J, LUCENTE V. Concomitant vaginal surgery with tension-free vaginal tape pubovaginal sling for treatment of female stress urinary incontinence and pelvic support defects. $27^{\text {th }}$ Scientific Meeting of the Society of Gynecologic Surgeons, Lake Buena Vista, FL, March 5-7, 2001. [PubMed]

15.NEUMAN M. TVT and TVT-Obturator; comparison of two operative procedures Eur J Obstet Gynecol Reprod Biol. 2007 Mar;131(1):89-92. Epub 2006 Apr 18
16.UEBERSAX J.S., WYMAN J. F., SHUMAKER S. A., MCCLISH D. K., FANTLN J. A., The Continence Program for Women Research Group. Short forms to assess life quality and symptom distress for urinary incontinence in women: The incontinence impact questionnaire and the urogenital distress inventory. Neurourology and Urodynamics, 1995; 14: 131-139.

17.COYNE KS, PAYNE C, BHATTACHARYYA SK, The impact of urinary urgency and frequency on health-related quality of life in overactive bladder: results from a national community survey. Value Health 2004; 7:455-463

Manuscript received: 24.04 .2017 